\title{
Synthesis of novel multi-cationic PEG-based ionic liquids $\dagger$
}

\author{
Martina Maya Cecchini, ${ }^{a b}$ Anissa Bendjeriou, ${ }^{c}$ Najib Mnasri, ${ }^{c}$ Clarence Charnay, ${ }^{* c}$ \\ Francesco De Angelis, ${ }^{b}$ Frédéric Lamaty, ${ }^{a}$ Jean Martinez ${ }^{a}$ and Evelina Colacino*a

\begin{abstract}
The syntheses of ten novel mono-, di- or tri-cationic poly(ethylene glycol)-based ionic liquids (ILPEGS), incorporating tetra-substituted ammonium cations, are described. The poly(ethylene glycol) chains could be bridged or not and bore the cation. In the di-cationic IL amphipathic poly(oxyethylene) spacers, with various lengths, were designed to connect the polar heads, while in the tri-cationic I $L_{P E G}$ family, the spacer was constituted by substituted diamines. The thermophysical properties such as viscosity or thermal stability were also investigated.
\end{abstract}

Ionic liquids (IL) $)^{1,2}$ and poly(ethylene glycol)s (PEG) ${ }^{3-5}$ have attracted tremendous interest within the last decades in various applications. They are different from usual organic solvents, considering their intrinsic chemical and physical properties. They have good stability (thermal, chemical, redox, radiochemical), low or null vapour pressure, high thermal and ionic conductivity suitable for microwave assisted heating, ${ }^{6,7}$ the possibility of recycling, and the ability to act as efficient solvents (also for gaseous reagents) and/or supports for reagent and catalyst immobilization. Among the diversity of functionalized ionic liquids, those incorporating poly(ethylene glycol) moieties ( $\mathrm{IL}_{\mathrm{PEG}}$ ) into either cationic or anionic units, making the link between the two distinct but very similar fluids, ${ }^{4,8-12}$ sharing common properties as those ones illustrated so far, yield a new appealing group of solvents finding applications across a range of disciplines including science, technology and engineering. ${ }^{8}$ Despite the plethora of possible applications for the $\mathrm{IL}_{\mathrm{PEG}}$ systems, only a limited number of examples were reported on their use as solvents for organic synthesis and catalysis. ${ }^{9}$ Different from PEGs or ionic liquids, PEG-based ionic liquids have been scarcely investigated and often neglected in recent literature.

We have recently reported on the use of alkylammonium monocationic $\left[\mathrm{mPEG}_{350} \mathrm{NMe}_{2}\right][\mathrm{Br}] \mathbf{1}$ and di-cationic $\left[\left(\mathrm{mPEG}_{350} \mathrm{NMe}_{2}\right)_{2}\right.$ $\left.\mathrm{CH}_{2} \mathrm{CH}_{2}\right][\mathrm{Br}] 3$ as useful solvents for the synthesis of dipeptides

\footnotetext{
${ }^{a}$ Institut des Biomolécules Max Mousseron (IBMM) UMR 5247 CNRS - UM I-UM II, Université Montpellier II, Green Chemistry and Enabling Technologies Team, Place E. Bataillon, 34095 Montpellier Cedex 5, FranceE-mail: evelina.colacino@univ-montp2.fr; Web: www.greenchem.univ-montp2.fr

${ }^{b}$ Dipartimento di Scienze Fisiche e Chimiche Università dell'Aquila e Consorzio INCA, Via Vetoio, Coppito, 67100 L'Aquila, Italy

${ }^{c}$ Institut Charles Gerhardt Montpellier (ICGM), Equipe CMOS, CNRS UMR 5253, Université Montpellier II, Place E. Bataillon, 34095 Montpellier Cedex 5, France. E-mail: clarence.charnay@univ-montp2.fr
}

under microwave irradiation ${ }^{13}$ (Fig. 1). We report herein the preparation of a novel family of poly(ethylene glycol)-based ionic liquids 2 and 4-12, having up to three ammonium groups in their structure (Fig. 1). Their physicochemical properties were also investigated in the perspective of using these new solvents as additives in organic synthesis and catalysis. Indeed, slight changes in the dimethyletherPEG chain (mPEG-cation) structure along with the chemical nature of the counter anion, with long functional MPEG derivatized cations, might have a significant effect on the thermophysical and viscosity properties of $\mathrm{IL}_{\mathrm{PEG}} \mathrm{S}$ and ionic liquids in general. ${ }^{8,9}$

The poly(ethylene glycol) (PEG) chains bridged (e.g. $\mathrm{IL}_{\mathrm{PEG}} \mathrm{S}$ and 6) or not (e.g. $\mathrm{IL}_{\mathrm{PEG}} \mathrm{S}$ 1-4 and 7-12) are on the cationic part of the molecule (Fig. 1). In the case of the di-cationic $\mathrm{IL}_{\mathrm{PEG}} \mathrm{S} 3-\mathbf{6}$, the tetra-alkylammonium cations are interconnected by a hydrophobic poly(methylene) (e.g. $\mathrm{IL}_{\mathrm{PEG}} \mathrm{S} 3$ and 4) spacer or by an amphiphilic poly(oxyethylene) unit (e.g. $\mathrm{IL}_{\mathrm{PEG}} \mathrm{S} 5$ and 6), while a diethyl- or dipropyl-amino spacer was selected to access to $\mathrm{IL}_{\mathrm{PEG}} \mathrm{S} \mathbf{7 - 1 2}$ (Fig. 1). We previously reported ${ }^{13}$ on the synthesis of mono-cationic $\mathrm{IL}_{\mathrm{PEG}} \mathrm{S} 1$ and 3 via a two-step procedure. In the

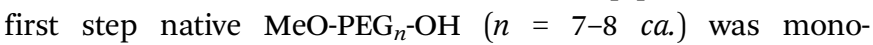
brominated with $\mathrm{PBr}_{3},{ }^{14}$ followed by direct alkylation of gaseous $\mathrm{N}, \mathrm{N}$-dimethylamine with a two-fold excess of MeO-PEG-350-Br 13, for $72 \mathrm{~h}$ at room temperature (Scheme 1). However, formation of di-brominated Br-PEG-Br (a by-product difficult to eliminate) during the first step, and the need to carefully control the exact amount of gaseous amine introduced into the reaction vessel, to avoid formation of a mixture consisting of unreacted starting material and the desired $\left[\mathrm{mPEG}_{350} \mathrm{NMe}_{2}\right][\mathrm{Br}] \mathbf{1}$, led us to design a more straightforward and faster synthetic scheme overcoming these difficulties and based on a three-step procedure (Scheme 1).

Improvement in the first step consisted in the use of $\mathrm{Et}_{3} \mathrm{~N}$ as base during $\mathrm{PBr}_{3}$ mono-bromination of poly(ethylene glycol) mono-methylether MeO-PEG-350-OH and MeO-PEG-750-OH. ${ }^{14}$ The role of the base was to neutralize hydrobromic acid formed 


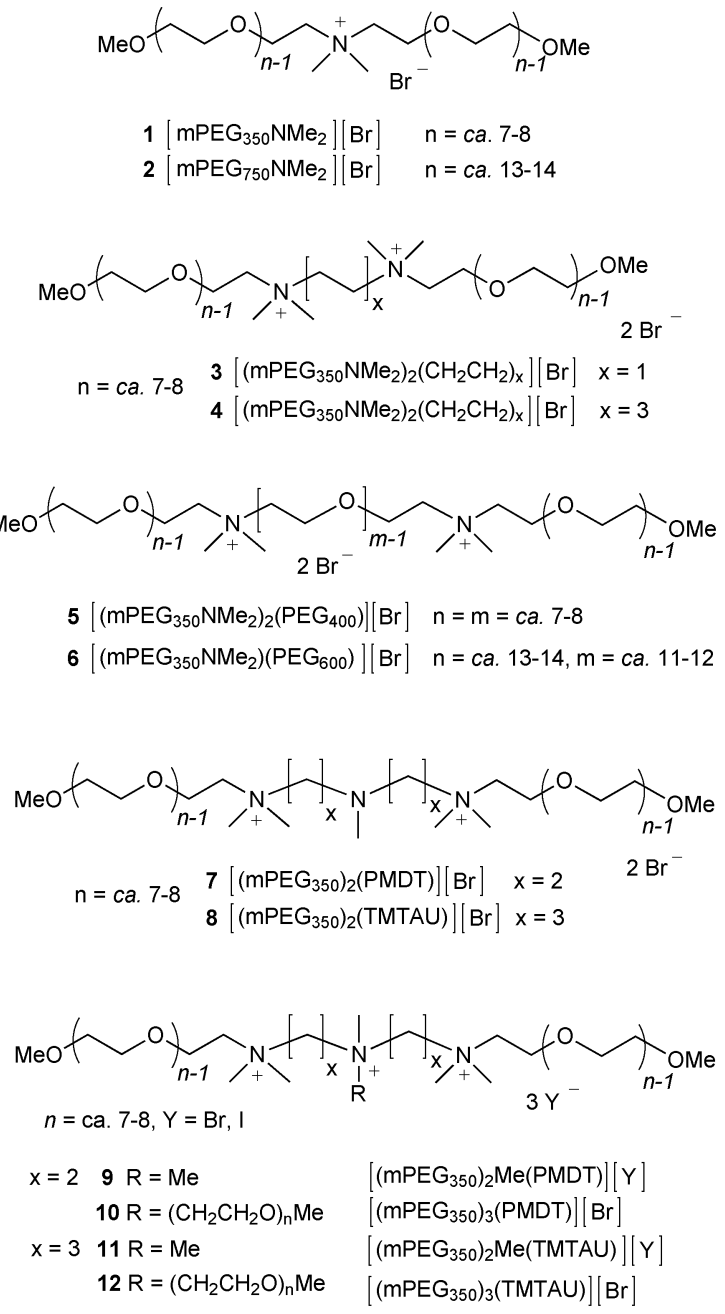

Fig. 1 Mono- and poly-cationic PEG-based ILs.

in the presence of traces of water and responsible for the

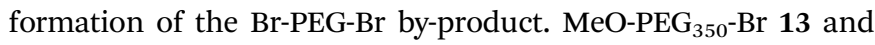

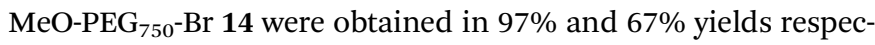
tively as pure compounds, after a simple chloroform extraction. Traces of unreacted MeO-PEG-OH or $\left[\mathrm{CH}_{3}\left(\mathrm{OCH}_{2} \mathrm{CH}_{2}\right)_{n}\right.$-O]$\mathrm{P}(=\mathrm{O}) \mathrm{OH}$ phosphoric diesters were eliminated in the aqueous layer. The second step consisted of the amination reaction of MeO-PEG-350-Br 13 and MeO-PEG-750-Br 14, leading to MeOPEG-350- $\mathrm{NMe}_{2} 15$ and MeO-PEG-750-NMe 16 respectively. In contrast to the two-step procedure ${ }^{13}$ (needing an exact control of stoichiometry and not always easy from the practical point of view), a large excess of gaseous $N, N$-dimethylamine (with respect to $\mathrm{MeO}^{\mathrm{PEG}} \mathrm{F}_{n} \mathrm{Br}$ ) was condensed at $-15{ }^{\circ} \mathrm{C}$ in anhydrous ethanol, and heated in a sealed vessel under microwave irradiation (Scheme 1). The presence of the poly(ethylene glycol) backbone was particularly adapted to microwave irradiation, ${ }^{4,15-19}$ in which the heating characteristic of the solvent plays a crucial role, ${ }^{7}$ speeding up the amination reaction and leading to $\mathrm{MeO}-$ PEG-350- $\mathrm{NMe}_{2} 15$ and MeO-PEG-750- $\mathrm{NMe}_{2} 16$ in good yields after simple extraction ( $99 \%$ and $96 \%$ yields respectively) in only 30 minutes (Scheme 1). Mono-cationic $\left[\mathrm{mPEG}_{350} \mathrm{NMe}_{2}\right][\mathrm{Br}] \mathbf{1}$ and
$\left[\mathrm{mPEG}_{750} \mathrm{NMe}_{2}\right][\mathrm{Br}] 2 \mathrm{IL}_{\mathrm{PEG}} \mathrm{S}$ were finally obtained by reacting stoichiometric quantities of $\mathrm{MeO}-\mathrm{PEG}_{n}-\mathrm{Br}$ derivatives 13-14 with MeO-PEG ${ }_{n}-\mathrm{NMe}_{2}$ 15-16 respectively, under microwave irradiation (Scheme 1). At $80{ }^{\circ} \mathrm{C}$ or $100{ }^{\circ} \mathrm{C}$, the nucleophilic substitution was not complete, even after prolonged heating ( 2 hours) or various irradiation cycles, with $120{ }^{\circ} \mathrm{C}$ performing the best. The improved synthetic pathway illustrated in Scheme 1 using microwave irradiation was more convenient in terms of reaction time, but was also more flexible than the one previously reported. ${ }^{13}$ It allowed the synthesis of various dissymmetric $\mathrm{IL}_{\mathrm{PEG}} \mathrm{S}$ by reaction of multiple combinations of PEG-Br/PEG-amine derivatives having different PEG-chain lengths.

The intermediate MeO-PEG $350-\mathrm{Br} \mathbf{1 3}$ was also used for the preparation of di-cationic $\mathrm{IL}_{\mathrm{PEG}} \mathrm{S}$ 3-4, characterized by the presence of a hydrophobic poly(methylene) spacer between the two ammonium cations (Scheme 1). Alkylation reactions of commercially available $N, N, N^{\prime}, N^{\prime}$-tetramethylethylenediamine (TMEDA, $x=1$ ) and $N, N, N^{\prime}, N^{\prime}$-tetramethyl-1,6-hexanediamine (TMHDA, $x=3$ ), in the presence of a two-fold excess of the key intermediate $\mathrm{MeO}-\mathrm{PEG}_{350}-\mathrm{Br}$ 13, were performed under conventional heating, at $70{ }^{\circ} \mathrm{C}$, affording after work-up, di-cationic $\mathrm{IL}_{\mathrm{PEG}} \mathrm{S} 3$ and 4 in $80 \%$ and $75 \%$ yields respectively (Scheme 1).

HO-PEG $400-\mathrm{OH}$ and $\mathrm{HO}-\mathrm{PEG}_{600}-\mathrm{OH}$ were the precursors for the synthesis of the amphiphilic poly(oxyethylene) spacer of the di-cationic $\mathrm{IL}_{\mathrm{PEG}} \mathrm{S}$ 5-6 (Scheme 2). Di-cationic $\mathrm{IL}_{\mathrm{PEG}} \mathrm{S}$ 3-4 (Scheme 1) and 5-6 (Scheme 2) differ by the nature and the length of the spacer between the two ammonium cations, having respectively an hydrophobic poly(methylene) spacer and an amphipathic poly(oxyethylene) moiety, which might influence their respective physical properties. Bromination reaction afforded PEG-400-Br 17 and PEG-600-Br 18 in good yields ( $99 \%$ and $84 \%$ yields respectively), after extraction from $\mathrm{CHCl}_{3}$. Microwave irradiation allowed straightforward amination in the presence of a gaseous $N, N$-dimethylamine excess, affording PEG-400-NMe $\mathrm{NM}_{2} 19$ (50\% yield) and PEG-600-NMe 20 ( $60 \%$ yield), after chloroform extraction. The solvent-free reaction between a two-fold excess of the key intermediate $\mathrm{MeO}^{-\mathrm{PEG}_{350}} \mathrm{-Br} \mathbf{1 3}$ with the corresponding PEG-dimethylamino derivatives $\mathrm{PEG}_{n}-\mathrm{NMe}_{2}$ (with $n=7-8 \mathrm{ca}$. or $n=11-12 c a$. for 19 and 20 respectively), under microwave heating, afforded $\mathrm{IL}_{\mathrm{PEG}} \mathrm{S}$ $\left[\left(\mathrm{mPEG}_{350} \mathrm{NMe}_{2}\right)_{2}\left(\mathrm{PEG}_{400}\right)\right][\mathrm{Br}] \mathbf{5}$ (96\% yield) and $\left[\left(\mathrm{mPEG}_{350} \mathrm{NMe}_{2}\right)_{2}{ }^{-}\right.$ $\left.\left(\mathrm{PEG}_{600}\right)\right][\mathrm{Br}] 6$ (73\% yield), with no need for purification (Scheme 2).

With the purpose to widen the diversity of this class of solvents, the synthesis of other new polycationic $\mathrm{IL}_{\mathrm{PEG}} \mathrm{S}$ 7-12 was also investigated (Fig. 1). Therefore, pentamethyl-diethylenetriamine (PMDT) and 2,6,10-trimethyl-2,6,10-triazaundecane (TMTAU) were alkylated in the presence of an excess of the intermediate MeO-PEG-350-Br 13, under neat conditions (Scheme 3). The synthetic strategy illustrated in Scheme 3 was versatile. At room temperature, only the di-alkylated di-cationic IL-PEG $\left[\left(\mathrm{mPEG}_{350}\right)_{2}(\mathrm{PMDT})\right][\mathrm{Br}] 7$ and $\left[\left(\mathrm{mPEG}_{350}\right)_{2}(\mathrm{TMTAU})\right][\mathrm{Br}] \mathbf{8}$ were obtained, as confirmed by ${ }^{1} \mathrm{H}$ NMR and MALDI-TOF analyses. By extending the reaction time to 6 days and increasing the temperature to $60^{\circ} \mathrm{C}$, the more challenging trialkylation was possible leading quantitatively to the tri-cationic $\left[\left(\mathrm{mPEG}_{350}\right)_{3}(\mathrm{PMDT})\right][\mathrm{Br}] \mathbf{1 0}$ 


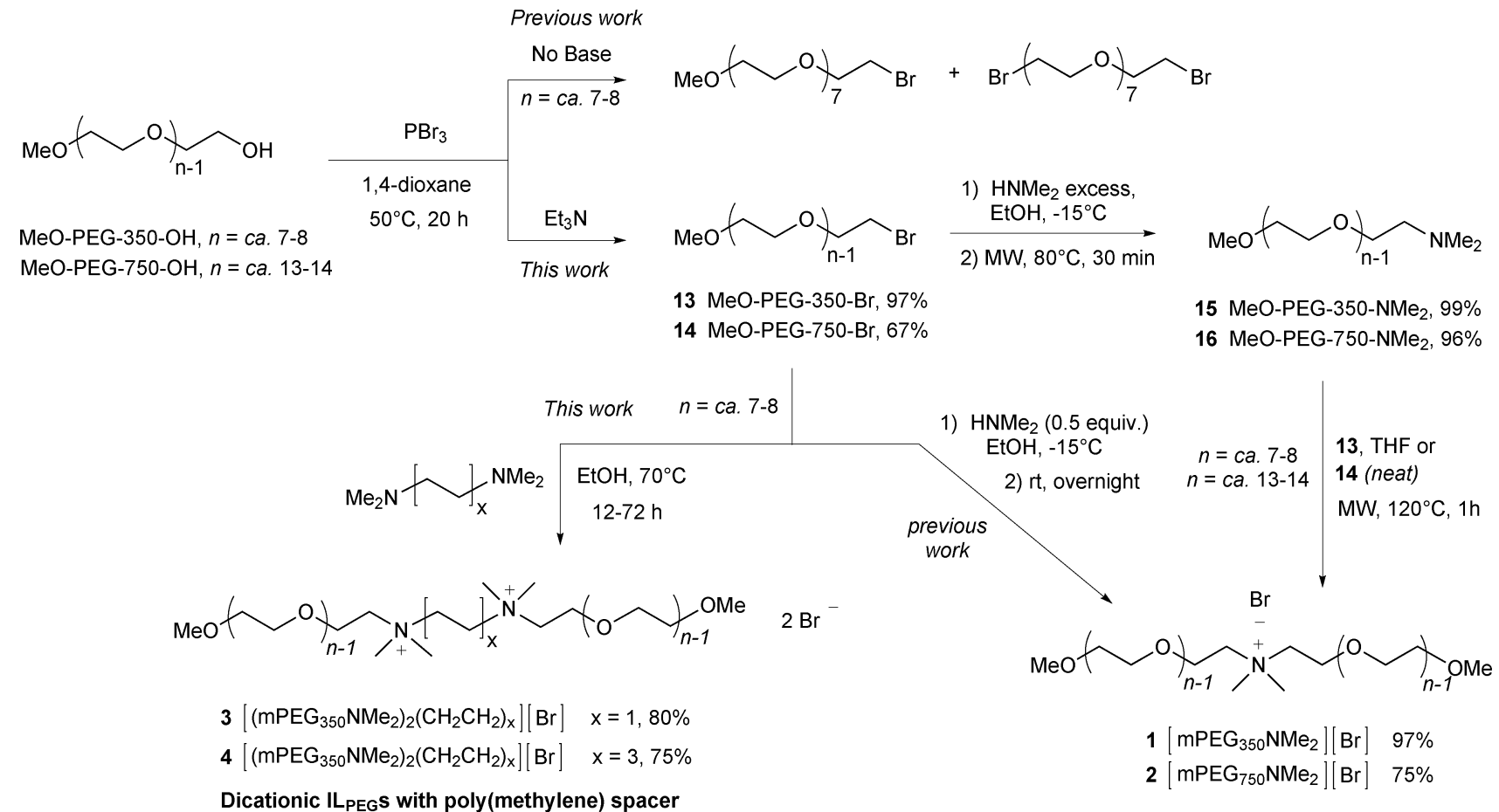

Monocationic IL $\mathrm{PEG}_{\mathrm{S}}$

Scheme 1 Synthesis of mono-cationic ILPEGS 1 and $\mathbf{2}$ and di-cationic ILPEGS $\mathbf{3}$ and $\mathbf{4}$ with hydrophobic spacers.

$$
\text { HO } \overbrace{\mathrm{m}-1} \mathrm{OH} \underset{\begin{array}{c}
1,4-\text { dioxane } \\
50^{\circ} \mathrm{C}, 20 \mathrm{~h}
\end{array}}{\stackrel{\mathrm{PBr}_{3}}{\longrightarrow}}
$$

PEG-400-OH, $m=c a .7-8$

PEG-600-OH, $m=$ ca. $11-12$

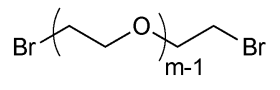

17 PEG-400-Br, 99\%

18 PEG-600-Br, 84\%

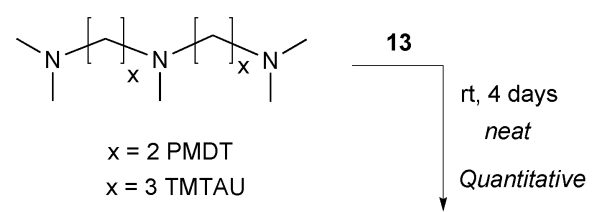

1) $\mathrm{HNMe}_{2}$ excess, $\mathrm{EtOH},-15^{\circ} \mathrm{C}$

2) $\mathrm{MW}, 80^{\circ} \mathrm{C}, 30 \mathrm{~min}$

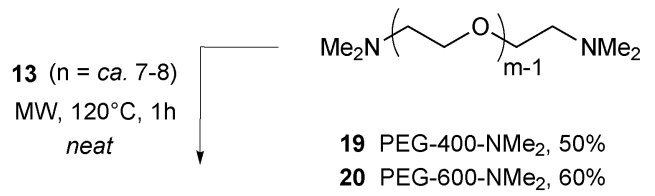

20 PEG-600-NMe, $60 \%$

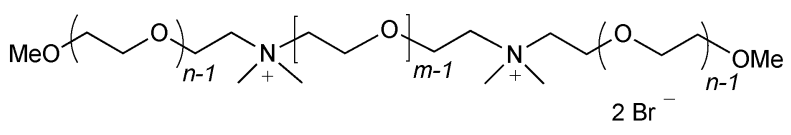

$5\left[\left(\mathrm{mPEG}_{350} \mathrm{NMe}_{2}\right)_{2}\left(\mathrm{PEG}_{400}\right)\right][\mathrm{Br}] \mathrm{n}=\mathrm{m}=$ ca. $7-8,96 \%$

$6\left[\left(\mathrm{mPEG}_{350} \mathrm{NMe}_{2}\right)\left(\mathrm{PEG}_{600}\right)\right][\mathrm{Br}] \mathrm{n}=\mathrm{ca} .13-14, \mathrm{~m}=\mathrm{ca} .11-12,73 \%$

\section{Dicationic ILPEG with poly (oxyethylene) spacer}

Scheme 2 Synthesis of ILPEGS $\mathbf{5}$ and $\mathbf{6}$ with amphipathic spacers.

or $\left[\left(\mathrm{mPEG}_{350}\right)_{3}(\mathrm{TMTAU})\right][\mathrm{Br}] 12$ counterparts, after removing the excess of the alkylating agent MeO-PEG-350-Br 13 with hexane (Scheme 3).

Similarly, tri-alkylated $\mathrm{IL}_{\mathrm{PEG}} \mathrm{S}\left[\left(\mathrm{mPEG}_{350}\right)_{2} \mathrm{Me}(\mathrm{PMDT})\right][\mathrm{Y}] \mathbf{9}$ and $\left[\left(\mathrm{mPEG}_{350}\right)_{2} \mathrm{Me}(\mathrm{TMTAU})\right][\mathrm{Y}] \mathbf{1 1}$ were obtained when methyl
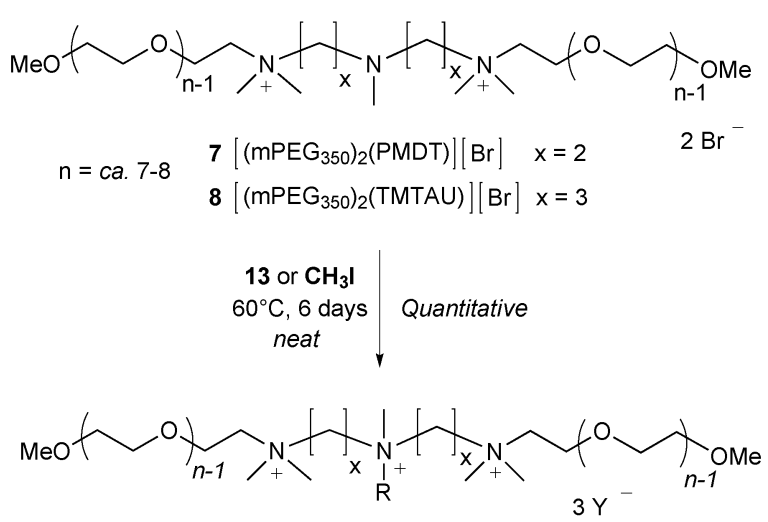

$$
\begin{aligned}
& \mathrm{x}=29 \mathrm{R}=\mathrm{Me} \quad\left[\left(\mathrm{mPEG}_{350}\right)_{2} \mathrm{Me}(\mathrm{PMDT})\right][\mathrm{Y}] \\
& 10 \mathrm{R}=\left(\mathrm{CH}_{2} \mathrm{CH}_{2} \mathrm{O}\right)_{n} \mathrm{Me} \quad\left[\left(\mathrm{mPEG}_{350}\right)_{3}(\mathrm{PMDT})\right][\mathrm{Br}] \\
& \mathrm{x}=3 \quad 11 \mathrm{R}=\mathrm{Me} \quad\left[\left(\mathrm{mPEG}_{350}\right)_{2} \mathrm{Me}(\mathrm{TMTAU})\right][\mathrm{Y}] \\
& 12 \mathrm{R}=\left(\mathrm{CH}_{2} \mathrm{CH}_{2} \mathrm{O}\right)_{n} \mathrm{Me} \quad\left[\left(\mathrm{mPEG}_{350}\right)_{3}(\mathrm{TMTAU})\right][\mathrm{Br}]
\end{aligned}
$$

Tricationic IL $L_{P E G S}$

Scheme 3 Synthesis of polycationic ILPEGS 7-12.

iodide was used as the alkylating agent (Scheme 3). The ${ }^{1} \mathrm{H}$ NMR spectra of di-alkylated $\mathrm{IL}_{\mathrm{PEG}} \mathrm{S} 7$ and 8 showed the presence of a singlet at $2.32 \mathrm{ppm}$, attributed to the methyl 
protons of the internal nitrogen atom. This signal disappeared after nitrogen quaternarization, giving a new singlet at $3.32 \mathrm{ppm}$ assigned to the three and six hydrogen atoms belonging to the methyl groups of the internal ammonium salt of $\mathrm{IL}_{\mathrm{PEG}} \mathrm{S} \mathbf{9 , 1 1}$ and of 10, 12 respectively. It is worth noting that when ethanol, acetonitrile and dioxane were used in the first step, the analysis performed on the crude revealed the presence of a mixture of di-alkylated $\left[\left(\mathrm{mPEG}_{350}\right)_{2}(\mathrm{PMDT})\right][\mathrm{Br}] 7\left[\left(\mathrm{mPEG}_{350}\right)_{2}(\mathrm{TMTAU})\right][\mathrm{Br}] \mathbf{8}$ and tri-alkylated $\left[\left(\mathrm{mPEG}_{350}\right)_{3}(\mathrm{PMDT})\right][\mathrm{Br}] \mathbf{1 0}\left[\left(\mathrm{mPEG}_{350}\right)_{3}(\mathrm{TMTAU})\right][\mathrm{Br}]$ $12 \mathrm{IL}_{\mathrm{PEG}} \mathrm{S}$ that could not be separated.

Then, attention was focused on the investigation of their physical properties such as thermal stability and viscosity, in view of their possible application as neoteric solvents in organic synthesis or as liquid supports for catalysis. Decomposition temperatures $T_{\mathrm{d}}$ measured for different $\mathrm{IL}_{\mathrm{PEG}} \mathrm{S}$ (Table 1 and Fig. 2) were close to $300{ }^{\circ} \mathrm{C}$, in agreement with the reported value for cationic ionic liquids composed of an ammonium positive group and a halide counter ion. ${ }^{13,20}$

The thermal stability of $\mathrm{IL}_{\mathrm{PEG}} \mathrm{S}$ was demonstrated to notably depend on the chemical nature of the counter anion and to a smaller extent on the chemical nature of the cation head and its side chain. ${ }^{21}$ Moreover it was expected that long PEG chains were flexible enough to wrap the cationic head. As a result, the induced steric hindrance by PEG chains did not facilitate the nucleophilic attack of the anion involved in the Hoffmann-type thermal decomposition of the ammonium bearing $\mathrm{IL}_{\mathrm{PEG}} \mathrm{S}$. Accordingly, $\left[\left(\mathrm{mPEG}_{350} \mathrm{NMe}_{2}\right)_{2}\left(\mathrm{PEG}_{600}\right)\right][\mathrm{Br}] 6$ having the longest PEG chain, displayed an increased stability (up to $310^{\circ} \mathrm{C}$ ). In addition, the increase of thermal stability of di-cationic $\mathrm{IL}_{\mathrm{PEG}} \mathrm{S}$ was observed to slightly increase with the spacer length (Fig. 2).

Di-cationic $\mathrm{IL}_{\mathrm{PEG}} \mathrm{S}\left[\left(\mathrm{mPEG}_{350} \mathrm{NMe}_{2}\right)_{2}\left(\mathrm{CH}_{2} \mathrm{CH}_{2}\right)\right][\mathrm{Br}] 3$ and $\left[\left(\mathrm{mPEG}_{350} \mathrm{NMe}_{2}\right)_{2}\left(\mathrm{CH}_{2} \mathrm{CH}_{2}\right)_{3}\right][\mathrm{Br}] \mathbf{4}\left(\right.$ or $\left[\left(\mathrm{mPEG}_{350}\right)_{3}(\mathrm{TMTAU})\right][\mathrm{Br}]$ 12) exhibited a $T_{\mathrm{d}}$ of $280{ }^{\circ} \mathrm{C}$ and $291{ }^{\circ} \mathrm{C}$ respectively, as the spacer length increased from 2 to 6 methylene units (Fig. 1). The viscosity $(\eta)$ of $\mathrm{IL}_{\mathrm{PEG}} \mathrm{S}$ used as media in different applications is an important parameter involved in the rate of mass transport, which may be a limiting factor for chemical or electrochemical applications (Table 1, Fig. 3). The viscosity of $\mathrm{IL}_{\mathrm{PEG}} \mathrm{S}$, based on a number of ethylene oxide units greater than three, largely depended on van der Waals interactions, hydrogen bonding, on the nature of the counter anion and on the rotational freedom within the cationic moieties. ${ }^{22}$ Moreover, the viscosity temperature dependence of $\mathrm{IL}_{\mathrm{PEG}} \mathrm{S}$ was also important as reactions in these new media are often carried out at temperatures higher than room temperature (Fig. 3). Accordingly, the reported viscosities in Table 1 were measured at $60{ }^{\circ} \mathrm{C}$,

Table 1 Thermophysical properties of ILPEGS

\begin{tabular}{|c|c|c|c|c|}
\hline $\mathrm{IL}_{\mathrm{PEG}}$ & & $\begin{array}{l}T_{\mathrm{d}} \\
\left({ }^{\circ} \mathrm{C}\right)\end{array}$ & $\begin{array}{l}\eta_{60^{\circ} \mathrm{C}} \\
(\mathrm{Pa} \mathrm{s})\end{array}$ & $\begin{array}{l}E_{\mathrm{a}} \text { : activation } \\
\text { energy }\left(\mathrm{kJ} \mathrm{mol}^{-1}\right)\end{array}$ \\
\hline$\left[\left(\mathrm{mPEG}_{350} \mathrm{NMe}_{2}\right)_{2}\left(\mathrm{CH}_{2} \mathrm{CH}_{2}\right)\right][\mathrm{Br}]$ & 3 & 280 & 2.04 & 0.806 \\
\hline$\left[\left(\mathrm{mPEG}_{350} \mathrm{NMe}_{2}\right)_{2}\left(\mathrm{CH}_{2} \mathrm{CH}_{2}\right)_{3}\right][\mathrm{Br}]$ & 4 & 291 & 2.75 & 0.818 \\
\hline$\left[\left(\mathrm{mPEG}_{350} \mathrm{NMe}_{2}\right)_{2}\left(\mathrm{PEG}_{600}\right)\right][\mathrm{Br}]$ & 6 & 310 & 0.25 & 0.392 \\
\hline$\left[\left(\mathrm{mPEG}_{350}\right)_{2}(\mathrm{PMDT})\right][\mathrm{Br}]$ & 7 & 293 & 18.1 & 0.813 \\
\hline$\left[\left(\mathrm{mPEG}_{350}\right)_{2} \mathrm{Me}(\mathrm{TMTAU})\right][\mathrm{Y}]$ & 11 & 284 & 15.8 & 0.896 \\
\hline$\left[\left(\mathrm{mPEG}_{350}\right)_{3}(\mathrm{TMTAU})\right][\mathrm{Br}]$ & 12 & 290 & 14.2 & 0.724 \\
\hline
\end{tabular}

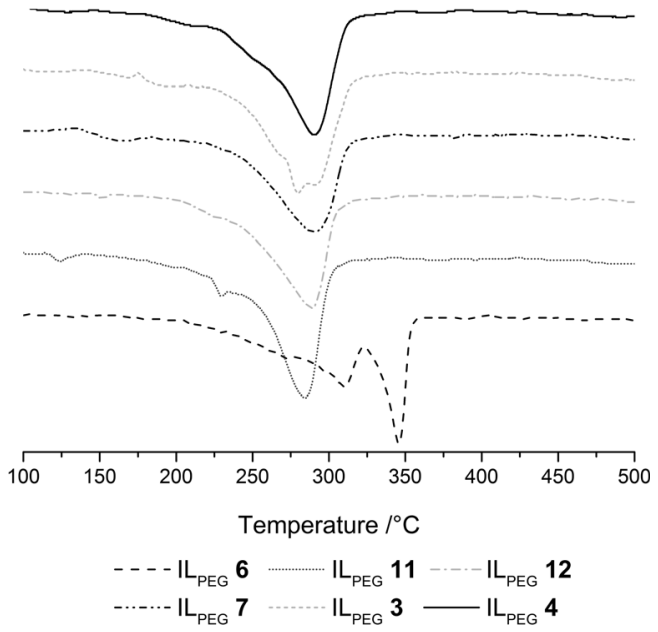

Fig. 2 Differential thermogravimetric profile of IL $L_{P E G S}$.

temperature at which we performed dipeptide synthesis under microwave irradiation using mono-cationic $\left[\mathrm{mPEG}_{350} \mathrm{NMe}_{2}\right][\mathrm{Br}]$ 1 or di-cationic $\left[\left(\mathrm{mPEG}_{350} \mathrm{NMe}_{2}\right)_{2}\left(\mathrm{CH}_{2} \mathrm{CH}_{2}\right)\right][\mathrm{Br}] 3$ as hydrophilic solvents. ${ }^{13}$

The increase of the spacer length $(x)$ from 1 to 3 was responsible for enhanced van der Waals interactions between alkyl groups, leading to a higher viscosity, $\eta_{60}{ }^{\circ} \mathrm{C}=2.04 \mathrm{~Pa} \mathrm{~s}$ and $2.75 \mathrm{~Pa} \mathrm{~s}$ for $\left[\left(\mathrm{mPEG}_{350} \mathrm{NMe}_{2}\right)_{2}\left(\mathrm{CH}_{2} \mathrm{CH}_{2}\right)\right][\mathrm{Br}] 3$ and $\left[\left(\mathrm{mPEG}_{350} \mathrm{NMe}_{2}\right)_{2}\left(\mathrm{CH}_{2} \mathrm{CH}_{2}\right)_{3}\right][\mathrm{Br}] \mathbf{4}$, respectively.

A large viscosity decrease was also observed by substituting the alkyl spacer by a poly(oxyethylene) group, $\eta_{60^{\circ} \mathrm{C}}=2.75 \mathrm{~Pa} \mathrm{~s}$ for $\left[\left(\mathrm{mPEG}_{350} \mathrm{NMe}_{2}\right)_{2}\left(\mathrm{CH}_{2} \mathrm{CH}_{2}\right)_{3}\right][\mathrm{Br}] \quad 4$ and $0.25 \mathrm{~Pa}$ s for $\left[\left(\mathrm{mPEG}_{350} \mathrm{NMe}_{2}\right)_{2}\left(\mathrm{PEG}_{600}\right)\right][\mathrm{Br}] \mathbf{6}$, which could be an advantage in terms of mass transport, when performing organic synthesis especially at temperatures below $60{ }^{\circ} \mathrm{C}$. Indeed, by increasing the density of PEG chains, it was expected that interactions of the ammonium group-PEG moieties decreased the associations

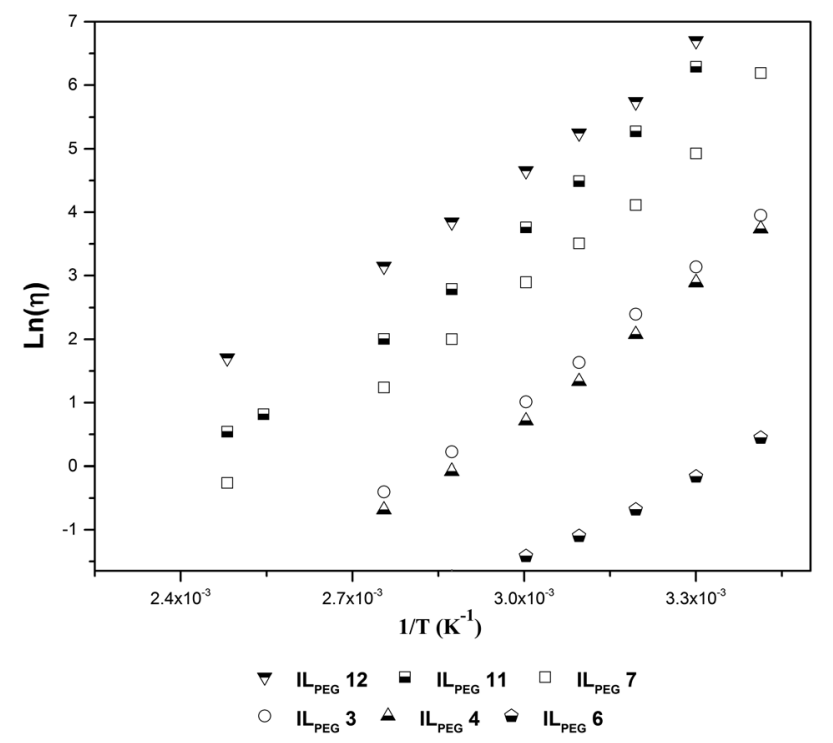

Fig. 3 Viscosity dependence on temperature. 
of anionic counter ions with cationic dimeric headgroups, leading to a viscosity decrease. Moreover, the $\mathrm{PEG}_{600}$ used as a spacer in $\left[\left(\mathrm{mPEG}_{350} \mathrm{NMe}_{2}\right)_{2}\left(\mathrm{PEG}_{600}\right)\right][\mathrm{Br}] 6$ was larger and much more flexible than the corresponding hexyl counterpart of $\mathrm{IL}_{\mathrm{PEG}}\left[\left(\mathrm{mPEG}_{350} \mathrm{NMe}_{2}\right)_{2}\left(\mathrm{CH}_{2} \mathrm{CH}_{2}\right)_{3}\right][\mathrm{Br}] \mathbf{4}$, and thereby the cation moiety displayed a faster relaxation time associated with a reduced viscosity. ${ }^{20}$ As reported in Table 1 , increasing the number of cationic groups in the ionic liquid molecules made the tri-cationic $\mathrm{IL}_{\mathrm{PEG}} \mathrm{S}\left[\left(\mathrm{mPEG}_{350}\right)_{2} \mathrm{Me}(\mathrm{TMTAU})\right][\mathrm{Y}] \mathbf{1 1}$ and $\left[\left(\mathrm{mPEG}_{350}\right)_{3}(\mathrm{TMTAU})\right][\mathrm{Br}] \mathbf{1 2}$ more viscous than di-cationic $\mathrm{IL}_{\mathrm{PEG}} \mathrm{S}$ $\left[\left(\mathrm{mPEG}_{350} \mathrm{NMe}_{2}\right)_{2}\left(\mathrm{CH}_{2} \mathrm{CH}_{2}\right)\right][\mathrm{Br}] 3,\left[\left(\mathrm{mPEG}_{350} \mathrm{NMe}_{2}\right)_{2}\left(\mathrm{CH}_{2} \mathrm{CH}_{2}\right)_{3}\right][\mathrm{Br}]$ 4 or $\left[\left(\mathrm{mPEG}_{350} \mathrm{NMe}_{2}\right)_{2}\left(\mathrm{PEG}_{600}\right)\right][\mathrm{Br}] \mathbf{6}$, as reported in Table 1 . The high viscosity of tri-cationic $\mathrm{IL}_{\mathrm{PEG}} \mathrm{S}$ including a short alkyl spacer (ethyl or propyl group) resulted in an increase of inter-ionic Coulombic interactions, enhancement of van der Waals interactions associated with reduced rotational freedom of the cation, larger and less flexible than di-cationic moieties. Surprisingly, the di-cationic $\left[\left(\mathrm{mPEG}_{350}\right)_{2}(\mathrm{PMDT})\right][\mathrm{Br}] \mathrm{7}$, having a diethylmethylamine spacer, exhibited the highest viscosity of the studied $\mathrm{IL}_{\mathrm{PEG}} \mathrm{S}$, due to the enhancement of the cohesion of the ionic liquid. Indeed, the presence of a ternary amine in di-cationic $\left[\left(\mathrm{mPEG}_{350}\right)_{2}(\mathrm{PMDT})\right][\mathrm{Br}] 7$ led to the apparition of a permanent dipole between the cationic ammonium groups and the high electronic density of the amine function. As a result, this additional dipolar interaction strongly increased the ionic liquid cohesion consistent with the high value of the viscosity. As shown in Fig. 3, the $\mathrm{IL}_{\mathrm{PEG}} \mathrm{S}$ viscosity decreased as $T^{\circ}$ increased according to an Arrhenius type law $\eta=\eta_{0} \mathrm{e}^{E_{\mathrm{a}} / \mathrm{RT}}$, while the activation energy $\left(E_{\mathrm{a}}\right)$ (Table 1) decreased for $\left[\left(\mathrm{mPEG}_{350} \mathrm{NMe}_{2}\right)_{2}\left(\mathrm{PEG}_{600}\right)\right][\mathrm{Br}] 6$ and $\left[\left(\mathrm{mPEG}_{350}\right)_{3}(\mathrm{TMTAU})\right][\mathrm{Br}] \mathbf{1 2}$ that contained the highest number of poly(oxyethylene) groups as side chains or spacers. This behavior was in agreement with the non-linear conformation of the PEG chains as previously reported. ${ }^{20}$

\section{Conclusions}

The preparation of various novel mono- and poly-cationic PEGbased ionic liquids under microwave irradiation was reported. According to our previous results ${ }^{13}$ their application as alternative reaction solvents was demonstrated. However, in contrast to their 'parent' compounds ionic liquids and PEGs, $\mathrm{IL}_{\mathrm{PEG}} \mathrm{S}$ have been less investigated and more research needs to be performed to shed light on their full potential and versatility as neoteric solvents to perform organic synthesis or for improved catalytic processes. The PEG chain(s) could act as metal stabilizing ligands, ${ }^{23}$ avoiding aggregation. Although classical ionic liquids are able to stabilize nanoparticles, the presence of a PEG chain enhances this property through steric stabilization. Consequently, the presence of the polyoxygenated backbone could be able to modulate the reactivity of the system, especially for metal-catalyzed processes, ${ }^{13}$ differently than the classical ionic liquids, where the modulation of the properties depends on the nature of the cation and/or the anion. Moreover, due to the presence of highly adsorbing PEG chains, microwave irradiation was particularly suitable, decreasing dramatically the reaction times with respect to conventional heating, ${ }^{4}$ also allowing syntheses under neat conditions. It should not be neglected that the presence of a biocompatible ${ }^{24}$ PEG moiety open new perspectives towards future studies on the ecotoxicity and biodegradability of this unexplored class of neoteric solvents. The physical properties of these ionic liquids were also investigated in terms of the nature of the spacer (hydrophobic or amphipathic) connecting the quaternary ammonium, ${ }^{9}$ as well as the PEG chain length. Other studies will be performed in the future to facilitate the process of a reaction by a simple product recovery. This would be possible after investigation of their thermomorphic properties (leading to a temperature-dependent biphasic system in the presence of a suitable organic solvent), or exploiting their solubility in water (due to the presence of PEG chains), allowing an easy extraction of the product. Current studies are in progress to show their possible applications.

\section{Acknowledgements}

One of us (M.M.C.) is grateful to the E.U. (Erasmus Program, Università de L'Aquila - Italy), Institut des Biomolécules Max Mousseron (IBMM, Montpellier - France) and Institut Charles Gerhardt (ICG, Montpellier - France) for the grant and to Pôle Chimie Balard (Montpellier - France) for the mobility fellowship 2012.

\section{Notes and references}

1 N. R. Candeias, L. C. Branco, P. M. P. Pedro, C. A. M. Afonso and A. F. Trindade, Chem. Rev., 2009, 109, 2703-2802.

2 P. Wasserscheid and T. Welton, Ionic Liquids in Synthesis, Wiley-VCH: Weinheim, 2003.

3 J. Chen, S. K. Spear, G. Huddleston and R. D. Rogers, Green Chem., 2005, 7, 64-82.

4 E. Colacino, J. Martinez, F. Lamaty, L. S. Patrikeevaa, L. L. Khemchyan, V. P. Ananikov and I. P. Beletskaya, Coord. Chem. Rev., 2012, 256, 2893-2920.

5 J. M. Harris and Z. S. Zalipsky, Poly(ethylene glycol): Chemistry and Biological Applications, American Chemical Society, Washington, 1997.

6 Microwaves in Organic Synthesis, ed. A. Loupy, Wiley-VCH, Weinheim, 2006.

7 C. O. Kappe, Angew. Chem., Int. Ed., 2004, 43, 6250-6284.

8 S. Tang, G. A. Baker and H. Zhao, Chem. Soc. Rev., 2012, 41, 4030-4066.

9 M. M. Cecchini, C. Charnay, F. De Angelis, F. Lamaty, J. Martinez and E. Colacino, ChemSusChem, 2014, 7, 45-65.

10 J. C. Ribot, C. Guerrero-Sanchez, T. L. Greaves, D. F. Kennedy, R. Hoogenboom and U. S. Schubert, Soft Matter, 2012, 8, 1025-1032.

11 M. Zacchigna, F. Cateni, S. Drioli and G. M. Bonora, Polymers, 2011, 3, 1076-1090.

12 T. Biedroń and P. Kubisa, J. Polym. Sci., Part A: Polym. Chem., 2008, 46, 6961-6968.

13 P. Petiot, C. Charnay, J. Martinez, L. Puttergill, F. Galindo, F. Lamaty and E. Colacino, Chem. Commun., 2010, 46, 8842-8844. 
14 O. S. Mills, N. J. Mooney, P. M. Robinson, C. I. F. Watt and B. G. Box, J. Chem. Soc., Perkin Trans. 2, 1995, 697-706.

15 R. Spina, E. Colacino, J. Martinez and F. Lamaty, Chem. Eur. J., 2013, 19, 3817-3821.

16 E. Colacino, L. Daich, J. Martinez and F. Lamaty, Synlett, 2007, 1279-1283.

17 E. Colacino, L. Villebrun, J. Martinez and F. Lamaty, Tetrahedron, 2010, 66, 3730-3735.

18 X. Bantreil, M. Sidi-Ykhlef, L. Aringhieri, E. Colacino, J. Martinez and F. Lamaty, J. Catal., 2012, 294, 113-118.

19 R. Spina, E. Colacino, B. Gabriele, G. Salerno, J. Martinez and F. Lamaty, Synlett, 2012, 23, 1481-1484.
20 L. V. N. R. Ganapatibhotla, J. Zheng, D. Roy and S. Krishnan, Chem. Mater., 2010, 22, 6347-6360.

21 M. Döbbelin, I. Azcune, M. Bedu, A. R. d. Luzuriaga, A. Genua, V. Jovanovski, G. Cabañero and I. Odriozola, Chem. Mater., 2012, 24, 1583-1590.

22 G. Yu, D. Zhao, L. Wen, S. Yang and X. Chen, AIChE J., 2012, 58, 2885-2899.

23 J. D. Holbrey, A. E. Visser, S. K. Spear, W. M. Reichert, R. P. Swatloski, G. A. Broker and R. D. Rogers, Green Chem., 2003, 5, 129-135.

24 Poly(ethylene glycol) Chemistry: Biotechnical and Biomedical Applications, ed. J. M. Harris, Plenum Press, New York and London, 1992. 